\title{
P04.60. The dutch complementary and alternative medicine (CAM) protocol: to ensure the safe and effective use of CAM within Dutch mental health
} care

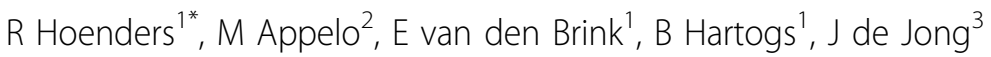 \\ From International Research Congress on Integrative Medicine and Health 2012 \\ Portland, Oregon, USA. 15-18 May 2012
}

\section{Purpose}

Complementary and alternative medicine (CAM) is subject to heated debates and prejudices. Studies show that CAM is widely used by psychiatric patients, usually without the guidance of a therapist and without the use of a solid working method, leading to potential health risks. How can we use CAM alongside conventional psychiatry in an outpatient psychiatric clinic in a judicious and professional way?

\section{Methods}

By searching through scientific and legal articles and discussion in focus groups a scientific model was formulated based on (1) patients' needs and wishes; (2) respect for their freedom of choice; (3) a mix of western medicine and CAM that are safe and effective; (4) protection against quackery and abuse; (5) Dutch law, the jurisprudence of the Medical Disciplinary Tribunal and the rules of the Dutch Association of Medical Practitioners (KNMG) and (6) scientific evidence.

\section{Results}

In the Centre for Integrative Psychiatry (CIP) of Lentis in the Netherlands some carefully selected CAM are offered under strict conditions, alongside conventional treatments. Because of the controversy and the potential health risks, Lentis designed a protocol which is presented. A clinical vignette is used to illustrate how this applies to daily practise.

${ }^{1}$ Center for Integrative Psychiatry, Lentis, Groningen, Netherlands Full list of author information is available at the end of the article

\section{Conclusion}

The Dutch CAM protocol provides a working method for the judicious use of CAM alongside conventional psychiatry in an outpatient psychiatric clinic.

\section{Author details}

${ }^{1}$ Center for Integrative Psychiatry, Lentis, Groningen, Netherlands. ${ }^{2}$ Het Behouden Huys, Groningen, Netherlands. ${ }^{3}$ University of Amsterdam, Amsterdam, Netherlands.

Published: 12 June 2012

doi:10.1186/1472-6882-12-S1-P330

Cite this article as: Hoenders et al:: P04.60. The dutch complementary and alternative medicine (CAM) protocol: to ensure the safe and effective use of CAM within Dutch mental health care. BMC Complementary and Alternative Medicine 2012 12(Suppl 1):P330.

Submit your next manuscript to BioMed Central and take full advantage of:

- Convenient online submission

- Thorough peer review

- No space constraints or color figure charges

- Immediate publication on acceptance

- Inclusion in PubMed, CAS, Scopus and Google Scholar

- Research which is freely available for redistribution 